\title{
Assessment of Early Outcomes of Surgical Treatment of Comminuted Fracture Calcaneus through Trans Calcaneal Approach
}

\author{
Mohsen Mohamed Abdo Mar'e'I , Reda Hussien Elka, Mohamed Abdelazeez Aly, Ziyad Ibrahim Ali* \\ Department of Orthopedic Surgery, Faculty of Medicine, Zagazig University, Egypt \\ *Corresponding Author: Ziyad Ibrahim Ali, Email: drziadrabti85@gmail.com
}

\begin{abstract}
Background: Treatment options for displaced intra-articular calcaneal fractures are still up for debate. The gold standard treatment for intra-articular calcaneal fractures is the conventional extensile lateral approach (ELA). Objective: achievement of good reduction with stable support for intra-articular calcaneal fractures by using trans calcaneal approach aiming for better functional outcome. Methods On the basis of a prospective cohort research, at Zagazig University Hospital Orthopedic Department we recruited 18 patients with comminuted fractures in the calcaneus who had been admitted to the hospital with intra-articular fractures, Extensive lateral approach and Tplate fixation were used to treat this condition 3 and 6 months after surgery, the American Orthopedic Foot And Ankle Society's functional assessment was performed. Results: All patients eventually achieved full union by the end of follow-up. Only one patient had delayed union. Most of patients $(55.56 \%)$ had good outcome according to AOFAS score. $11.11 \%$ had excellent outcome. While about one third of patients had unsatisfactory outcome, either fair (27.77\%) or poor (5.56) AOFAS score. In regard to complications, most of the studied group (61.11\%) didn't have any complications, three patients had surgical site infection, and $11.11 \%$ of patients had sural neuritis. Conclusion: The trans-calcaneal method of reduction through ELA is an excellent method for treatment of displaced intra-articular calcaneal fractures, as it provides good exposure and facilitates anatomical reduction of fracture.
\end{abstract}

Keywords: Calcaneal fractures, Extensile lateral approach (ELA).

\section{INTRODUCTION}

There are seven tarsal bones in all, the largest of which being the calcaneus. Stand, walk, and run are all possible because of its connection to the Achilles tendon. Correct gait relies on the normal development of the subtalar and mid-tarsal joints ${ }^{(\mathbf{1})}$. In addition to supporting the weight of the body, the calcaneus serves as a lever for the calf muscles, allowing them to exert more effort. On lateral radiography, the anatomy is depicted from two distinct perspectives. It is clear that Bohler's angle has the most significant impact on walking dynamics. The angle of Gissane is the second one ${ }^{(2)}$.

About $2 \%$ of all fractures and $60 \%$ of all tarsal injuries are caused by calcaneus fractures. Using the Sander's approach to describe intra-articular fractures of the calcaneus is the most usual method ${ }^{(3)}$. Treatment options for displaced intra-articular calcaneal fractures are still up for debate. In recent years, the classic lateral approach to intra-articular calcaneal fractures has been regarded as the gold standard way of treatment ${ }^{(4)}$.

Using this technique, the sural nerve is more protected and the posterior facet fragment and lateral wall can be reduced directly. However, orthopedic specialists are concerned about the high rate of wound complications. Some patients who undergo open reduction and internal fixation via the extensile lateral approach are at risk of developing superficial wound edge necrosis, which is accompanied by a number of other complications, including peroneal tendonitis, sural nerve injury, vascularization injury, infections, and amputations ${ }^{(5)}$.

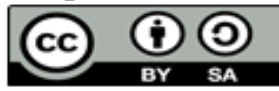

This article is an open access article distributed under the terms and conditions of the Creative Commons Attribution (CC BY-SA) license (http://creativecommons.org/licenses/by/4.0/)
Many surgical procedures have been developed in an effort to minimize these consequences, such as tarsi). Smaller, less invasive incisions minimize soft tissue dissection and allow better vision and control of the articular reduction ${ }^{(6)}$. A good stable fixation is needed for better outcomes and results when dealing with intra-articular fractures. Minimally invasive surgical procedures have a limited surgical field of view, which makes it difficult to achieve a satisfying closure reduction ${ }^{(7)}$.

We aimed at this study for achievement of good reduction with stable support for intra-articular calcaneal fractures by utilization of trans calcaneal technique aiming for better functional outcome.

\section{PATIENTS AND METHODS}

At Orthopedic Department, Zagazig University Hospital, Egypt. This research included 18 patients with complaining intra-articular calcaneal fractures, treated through extensile lateral approach, and fixed by T-plate.

\section{Ethical considerations:}

As long as all participants signed informed consent forms and submitted them to Zagazig University's Research Ethics Committee, the study was allowed (ZU-IRB\#6280). We followed the World Medical Association's ethical code for human experimentation, the Helsinki Declaration. the limited lateral approach: (plantar, ollier, and sinus 
This clinical trial study included 18 participants; the age of the studied group ranged from 19 to 50 years; $38.89 \%$ of the group had age ranged from 30 to 40 years. Majority of them were males, and the affected side was equal. 66.67 of them were injured due to fall from height (FFH) as the major mechanism followed by road traffic accident (RTA). $77.78 \%$ had no associated injury while $22.22 \%$ had associated injury. Sanders II represented the most common type according to Sander's classification. Most of patients were operated upon in period less than 10 days of the injury (ranged from 4 to 9 days).

Exclusion Criteria: severe skin and soft tissue damage, including open fractures by the time of the procedure, the foot's lateral aspect was covered with edema and blisters that had not been cured. Preexisting comorbidities that rule out surgery, such as vascular problems, heart disease, and uncontrolled diabetic patients.

\section{All patients were subjected to the following:}

1. Complete history taking.

2. Complete general and clinical examination performed by the referring surgeon.

3. A Plain radiography (X-ray) in three views: (anterio-posterior, lateral, Harris axial)

B- Computed tomography, for better determination of degree of comminution and displacement of fracture and to be used for classification.

4. All patients had full preoperative lab investigation before surgery including: Liver and kidney function tests, random blood sugar, complete blood picture, viral screen, and coagulation studies (PT/PTT).

\section{Steps of Surgery:}

Strict attention to bony prominence was paid to the damaged foot in lateral decubitus posture with the injured foot elevated. Operation was carried out under general anesthesia. Patient was positioned in a lateral position. Entire limb was prepared up to knee joint and draped.

Patients approached via extensile lateral marking the bony landmarks. The extensile lateral approach was a L-shaped incision starting with a vertical line $2 \mathrm{~cm}$ above the fibula $1 \mathrm{~cm}$ lateral to the edge of tendon Achilles and directed downward then curved 90 degrees to proceed with horizontal line at the change of skin texture (glabrous and nonglabrous) around the fifth metatarsal's base. A full-thickness flap was created by making an incision all the way through the bone. In order to protect the sural nerve and peroneal tendons, a careful dissection was performed. Three $\mathrm{K}$ wires might be inserted on the fibula, talus, and cuboid bone to keep the skin flap in place.

Under fluoroscopic guidance, a Steinmann pin was introduced from the medial to the lateral aspect of the posterior calcaneus. The calcaneal height and length were restored with valgus and varus alignment after the medial-to-lateral, posterior-to-anterior, and tuberosity fragment reductions. We could see through to its medial side by reflecting the lateral joint fragment, which has the sustentacular and body fragments above and below it.

Disimpaction and correction of the varus deformity were performed while a tiny periosteal elevator was inserted into the medial wall fracture site.

As part of this procedure, the posterior subtalar joint facet was rotated back into place and lowered to its original position on the sustentacular fragment.

A transversal Kirschner wire could keep this decrease in place for the time being. Afterwards, visual and radiographic confirmation of reduction was made by inverting the hindfoot. As an alternative to the T-shaped plate, in some cases, the screw was pushed into the sustentaculum tail through the tuberosity and into the good bone on medial side of calcaneus, anterior and medial. Placing a small Tshaped plate $3: 5 \mathrm{~mm}$ in size and location before fixing, the plate was attached with suitable screws after it has been positioned in its proper position.

On the $3^{\text {rd }}$ and $6^{\text {th }}$ months after surgery, according to the American Orthopedic Foot and Ankle Society (A.O.F.A.S.) we performed a functional assessment.

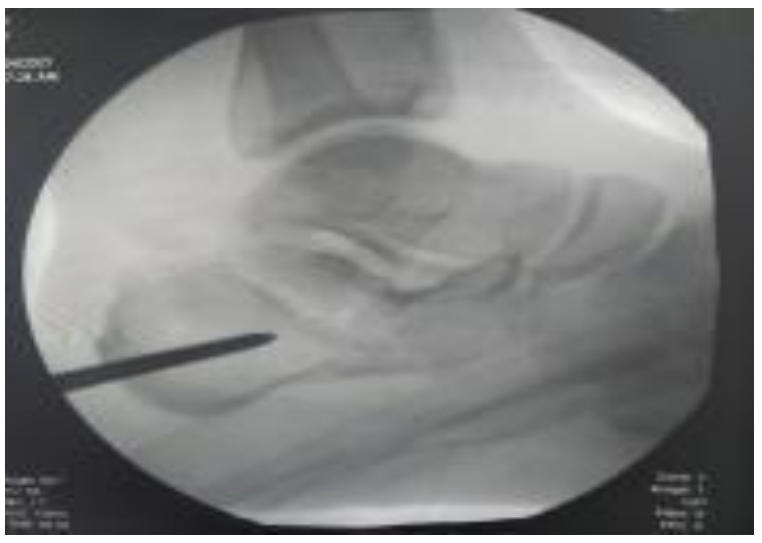

Fig. (1): Insertion of Steinmann pin under fluoroscopy guide.

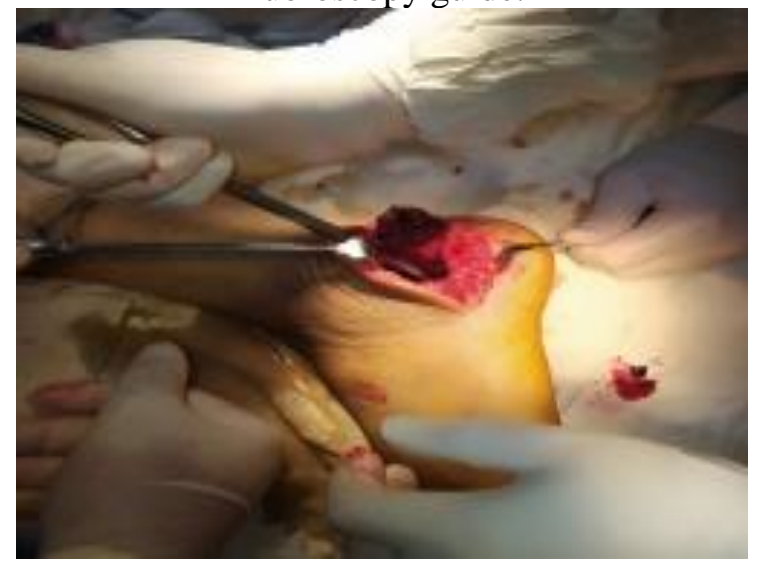

Fig. (2): Reflecting lateral wall fragment. 


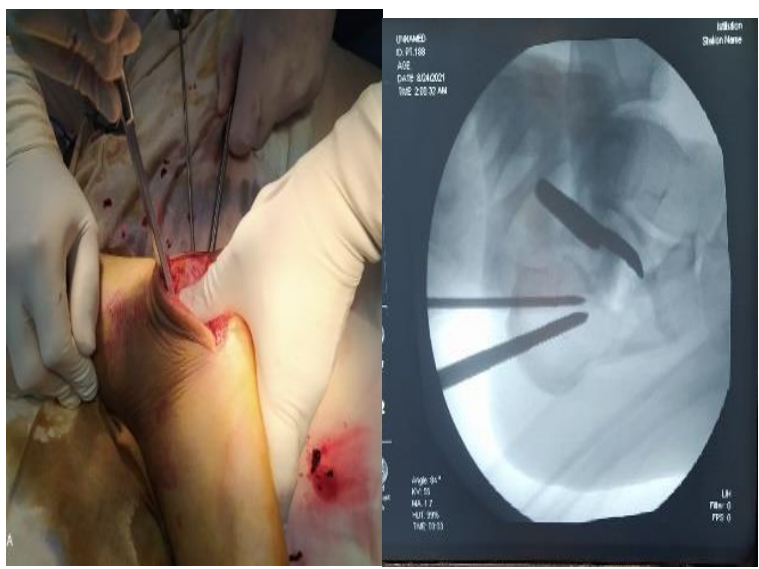

Fig. (3): Reduction of medial wall and levering of posterior joint facet by using of small periosteal elevator.

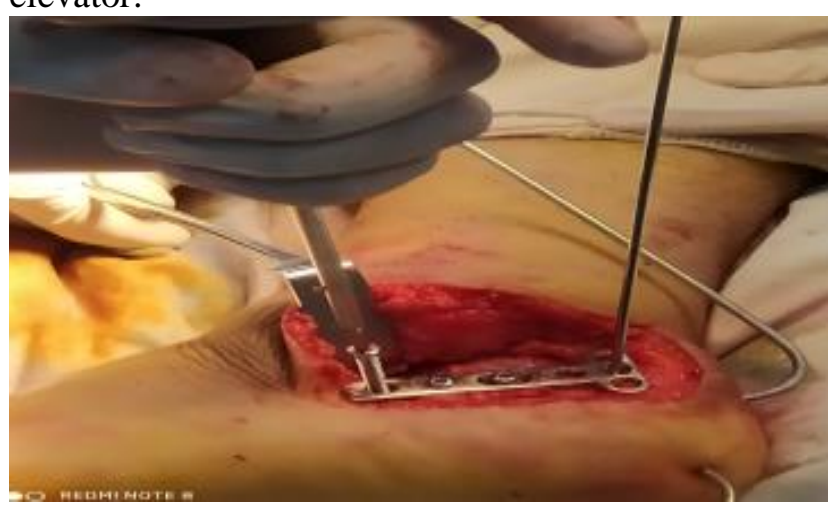

Fig. (4): Fixation of fracture by plate.

Statistical analysis:

The collected data were coded, processed and analyzed using the SPSS (Statistical Package for Social Sciences) version 22 for Windows ${ }^{\circledR}$ (IBM SPSS Inc, Chicago, IL, USA). Paired t-test was employed to compare paired quantitative data in the analysis of the differences between the groups. Quantitative data were expressed as mean \pm SD (Standard deviation). Proportions were compared using the Chi-square test $\left(\mathrm{X}^{2}\right)$. $\mathrm{P}$ value 0.05 was considered statistically significant (S). It was judged highly significant (HS) when the P value was 0.001 .

\section{RESULTS}

Most of patients had full radiologically and clinically union within 13 weeks postoperatively. While 7 patients needed 14 weeks or more to achieve full union. One of them had delayed union and need 22 weeks to full union achieved (Table 1).

Table (1): Time of union among the studied group

\begin{tabular}{||c|c|c|}
\hline Union Time & NO(18) & \% \\
\hline \hline 12-13 weeks & 11 & $61.11 \%$ \\
\hline$\geq \mathbf{1 4}$ weeks & 7 & $38.89 \%$ \\
\hline
\end{tabular}

Seven patients had Bohler angle less than $10^{\circ}$ preoperatively. This is improved postoperatively as all patients had Bohler angle $14^{\circ}$ or more (Table 2).
Table (2): Radiological evaluations of calcaneus angles pre- and postoperatively

\begin{tabular}{|c|c|c|}
\hline $\begin{array}{c}\text { Preoperative } \\
\text { Bohler angle }\end{array}$ & NO $(18)$ & $\%$ \\
\hline \hline Mean \pm SD & \multicolumn{2}{|c|}{$11.4^{\circ} \pm 4.1$} \\
\hline$<10^{\circ}$ & 11 & $61.1 \%$ \\
\hline $\mathbf{1 0 - 2 0}^{\circ}$ & 7 & $38.9 \%$ \\
\hline $\begin{array}{c}\text { Postoperative } \\
\text { Bohler angle }\end{array}$ & NO (18) & $\%$ \\
\hline \hline Mean \pm SD $^{|c|} 27.7^{\circ} \pm 5.9$ \\
\hline $\mathbf{1 4 - 2 4}^{\circ}$ & $6^{\circ}$ & $33.3 \%$ \\
\hline $25-35^{\circ}$ & $12^{\circ}$ & $66.7 \%$ \\
\hline
\end{tabular}

All angles and dimensions of calcaneus were improved postoperatively. Especially Bohler Angle and Gissane Angle, which were statistically significant improved postoperatively (Table 3).

Table (3): Improvement of angels and dimensions of calcaneus between preoperative and final follow up (Number of patients is 18)

\begin{tabular}{|c|c|c|c|}
\hline $\begin{array}{c}\text { Calcaneal } \\
\text { radiological } \\
\text { measurements }\end{array}$ & $\begin{array}{c}\text { Preoperative } \\
(\text { mean } \pm \text { SD })\end{array}$ & $\begin{array}{c}\text { Postoperative } \\
(\text { mean } \pm \text { SD })\end{array}$ & $\begin{array}{c}\text { Paired } \\
\text { T. test } \\
\text { p value }\end{array}$ \\
\hline \hline Bohler Angle & $9.94 \pm 2.81$ & $27.72 \pm 3.95$ & $\mathbf{0 . 0 0 2} *$ \\
\hline Gissane Angle & $132.17 \pm 32.04$ & $120.15 \pm 29.98$ & $\mathbf{0 . 0 4} *$ \\
\hline Calcaneal width & $40.89 \pm 9.84$ & $38.25 \pm 8.69$ & 0.07 \\
\hline Calcaneal length & $65.53 \pm 15.81$ & $69.24 \pm 16.89$ & 0.065 \\
\hline
\end{tabular}

*: Significant $\mathrm{P}$,

Most of patients $(55.56 \%)$ had good outcome according to AOFAS score (Table 4).

Table (4): Final outcome by AOFAS score among the studied group.

\begin{tabular}{|c|c|c|}
\hline AOFAS score Final Outcome & NO (18) & \% \\
\hline \hline Excellent & 2 & $11.11 \%$ \\
\hline Good & 10 & $55.56 \%$ \\
\hline Fair & 5 & $27.77 \%$ \\
\hline Poor & 1 & $5.56 \%$ \\
\hline
\end{tabular}

$61.1 \%$ of patients had no complications. While surgical site infection (SSI) represented the most common complication, and it was treated with oral antibiotics and serial dressing and it resolved within 10 days postoperatively, one patient of these three patients had subtalar arthritis along with SSI and scheduled for arthrodesis. While sural neuritis occurred in $11.1 \%$, both cases were treated by administration of oral vitamin B complex and healed during 3 months. Peroneal tendinitis and delayed union occurred in one patient for each complication. Comparison between the complicated and noncomplicated cases regarding patients characteristics among the studied group; age, time before surgery, union time and AOFAS score had statistical significant effect on presence of complications (Table 5). 
Table (5): Comparison between the complicated and non-complicated cases regarding patients' characteristics among the studied group.

\begin{tabular}{|c|c|c|c|c|c|}
\hline \multirow[b]{2}{*}{ Variable } & \multicolumn{2}{|c|}{ Complicated } & \multicolumn{2}{|c|}{ Uncomplicated } & \multirow[b]{2}{*}{$\mathbf{p}$} \\
\hline & $\begin{array}{l}\text { NO. } \\
\text { (7) }\end{array}$ & $\%$ & $\begin{array}{l}\text { NO. } \\
\text { (11) }\end{array}$ & $\%$ & \\
\hline $\begin{array}{l}\text { Age group } \\
18-29 \text { years } \\
30-39 \text { years } \\
40-50 \text { years }\end{array}$ & $\begin{array}{l}2 \\
1 \\
4\end{array}$ & $\begin{array}{l}28.57 \\
14.29 \\
57.14\end{array}$ & $\begin{array}{l}4 \\
6 \\
1\end{array}$ & $\begin{array}{c}36.36 \\
54.54 \\
9.1\end{array}$ & 0.06 \\
\hline $\begin{array}{l}\text { Sex } \\
\text { Male } \\
\text { Female } \\
\end{array}$ & $\begin{array}{l}5 \\
2 \\
\end{array}$ & $\begin{array}{l}71.4 \\
28.6 \\
\end{array}$ & $\begin{array}{l}8 \\
3 \\
\end{array}$ & $\begin{array}{l}72.7 \\
27.3 \\
\end{array}$ & 0.95 \\
\hline $\begin{array}{l}\text { Mechanism of injury } \\
\text { FFH } \\
\text { RTA } \\
\end{array}$ & $\begin{array}{l}6 \\
1 \\
\end{array}$ & $\begin{array}{l}85.7 \\
14.3 \\
\end{array}$ & $\begin{array}{l}6 \\
5 \\
\end{array}$ & $\begin{array}{l}35.7 \\
42.9 \\
\end{array}$ & 0.17 \\
\hline $\begin{array}{l}\text { Associated injuries } \\
\text { Absent } \\
\text { Present }\end{array}$ & $\begin{array}{l}4 \\
3\end{array}$ & $\begin{array}{l}57.14 \\
42.86\end{array}$ & $\begin{array}{c}10 \\
1\end{array}$ & $\begin{array}{c}90.9 \\
9.1\end{array}$ & 0.09 \\
\hline $\begin{array}{l}\text { Sandres classification } \\
\text { II } \\
\text { III } \\
\end{array}$ & $\begin{array}{l}2 \\
5 \\
\end{array}$ & $\begin{array}{l}28.6 \\
71.4 \\
\end{array}$ & $\begin{array}{l}8 \\
3 \\
\end{array}$ & $\begin{array}{l}72.7 \\
27.3 \\
\end{array}$ & 0.06 \\
\hline $\begin{array}{l}\text { Time before surgery } \\
<10 \text { days } \\
\geq 10 \text { days }\end{array}$ & $\begin{array}{l}2 \\
5\end{array}$ & $\begin{array}{l}28.6 \\
71.4\end{array}$ & $\begin{array}{l}9 \\
2\end{array}$ & $\begin{array}{l}81.8 \\
18.2 \\
\end{array}$ & $0.024 *$ \\
\hline $\begin{array}{l}\text { Union time } \\
12-13 \text { weeks } \\
\geq 14 \text { weeks }\end{array}$ & $\begin{array}{l}1 \\
6\end{array}$ & $\begin{array}{l}14.3 \\
85.7\end{array}$ & $\begin{array}{l}9 \\
2\end{array}$ & $\begin{array}{l}81.8 \\
18.2\end{array}$ & $0.005^{*}$ \\
\hline
\end{tabular}

*: Significant P

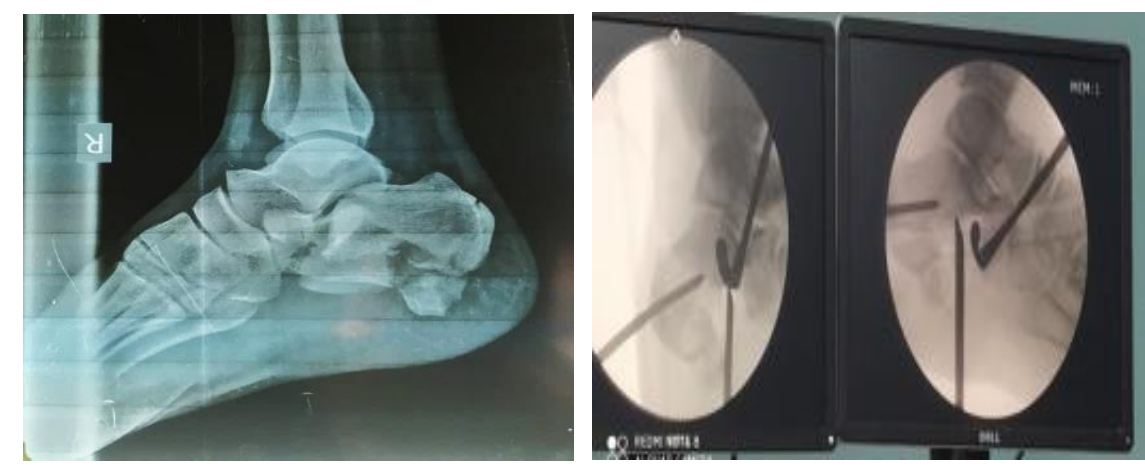

X-ray intraoperative X-ray Lateral view of calcaneus
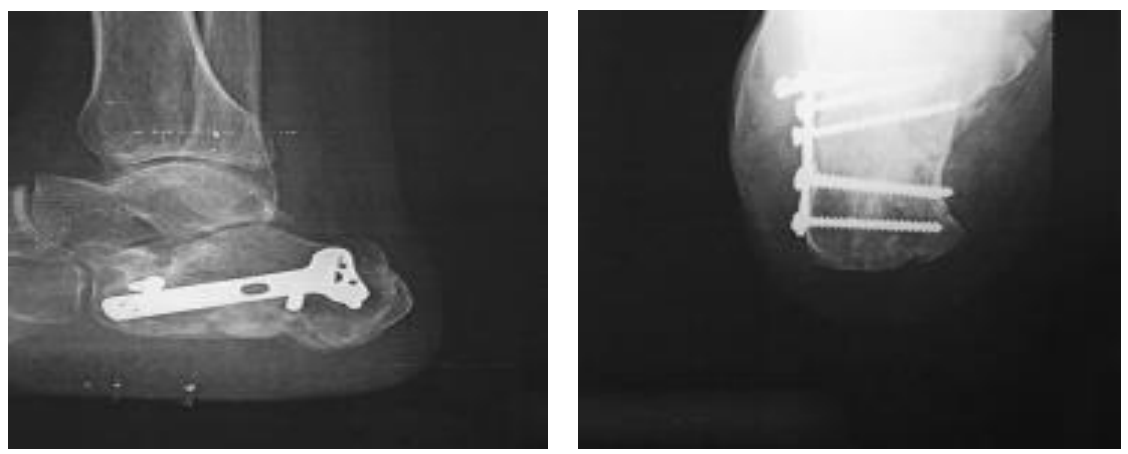

Fig. (5): X-ray follow up at 6 months. A 32 years old male, had history of fall down from height with trauma to right ankle. Patient was complaining of pain, swelling and inability to bear weight. X-rays shows fracture right calcaneal bone, CT scan relives fracture calcaneus intraarticular classified as Sanders type II. At first managed with back slab limb elevation and analgesic, then after 6 days patient was operated upon with lateral extensile approach with trans calcaneal reduction. 


\section{DISCUSSION}

In this study 18 patients were admitted to Zagazig University Hospitals, from the period of June 2021 to January 2022, complaining intra-articular calcaneal fractures, treated through extensile lateral approach, and fixed by T-plate.

Our patients mean age $34.72 \pm 9.09$ years ranged from 19 to 50 years; most of them were on their $3^{\text {rd }}$ decade of life, males represented $72.2 \%$, and the females represented $27.8 \%$. The right side was affected in $61.1 \%$ and $38.9 \%$ of them were affected on the left side. No patient included in this study had bilateral affection.

Most of patients $(66.67 \%)$ were injured due to FFH. And most of patients (77.78\%) had no associated injuries, only 4 patients had associated injuries; two of them had ipsilateral either subtrochanteric femoral fracture or L2 spinal fracture. While the other two patients had either contralateral tibial shaft fracture or calcaneal fracture, this calcaneal fracture was not included in this study because it was treated by K-wires. Most of patients (55.56\%) was Sanders type II, while the rest was type III according to Sanders classification. Two thirds of our patients were operated upon before 10 days (from $4^{\text {th }}$ to $9^{\text {th }}$ days). And only 6 patients need more than 10 days between injury and operation. The skin situation must be good to avoid postoperative complications, which could be occurred due to poor blood supply to the lateral aspect of the skin over calcaneus. But also, prolongation of the time of operation may lead to difficulties in reduction due to callus formation.

This was agreed with Santosha et al. ${ }^{(8)}$ who had 24 patients, with average age of 37.5 years ranged from 17 to 59 years. $83.3 \%$ of them were males. And the right side was the most affected side. $87.5 \%$ of patients were injured due to FFH. Most of patients (61.1\%) were type II, while the rest $38.8 \%$ were type III according to Sanders classification. Most of fractures were isolated $(72.4 \%)$, while spine fractures occurred in $16.6 \%$ as the most common associated fracture.

Regarding functional outcome, according to AOFAS score, our results most of patients had satisfactory results $(66.7 \%)$, while $33.3 \%$ had unsatisfactory results either fair or poor outcomes. All patients aged below 30 years had good results, except one patient had excellent results. While $71.4 \%$ of patients of patients between 30 and 40 years were good, while one patient $14.3 \%$ was excellent and another one patient was fair, this patient was heavy smoker and had Sanders III calcaneal fractures, associated with ipsilateral subtrochanteric fracture and subtalar arthritis along with SSI as complications. On other hand all the patients above age of 40 years had unsatisfactory outcome, $80 \%$ of them had fair and one patient had poor outcome according to AOFAS score.

This was comparable with Mallya et al. ${ }^{\left({ }^{(9)}\right.}$ whose patients had mean age of 36.67 years ranged from 18 to 65 years and the AOFAS scores were $52.5 \%$ had satisfactory outcome (almost all of them were good, and only one patient had excellent AOFAS score). And the rest $47.5 \%$ were unsatisfactory as $37.5 \%$ were fair and $10 \%$ had poor AOSAS score. Also Yeo et al. ${ }^{(10)}$ documented that the mean age of the ELA group was 37.5 years ranged from 17 to 59 years. The AOFAS score was $43.3 \%$ excellent, $33.3 \%$ good, $10 \%$ fair and $13.3 \%$ were poor functional outcome.

Our results showed that the mean union time was 13.3 weeks ranged from 12 to 16 weeks. 11 patients $(61.1 \%)$ had union time before 14 weeks, while 7 patients $(38.9 \%)$ had union time after 14 weeks.

All patients with union time between 12 and 13 weeks had satisfactory outcome, except one male patient aged more than 42 years. While only two cases with union time more than 14 weeks had satisfactory (good) result while the rest 5 patients had either fair or poor AOFAS score.

This was agreed with Santosha et al. ${ }^{(8)}$ who documented that the mean union time was 12.5 weeks. Meraj et al. ${ }^{(\boldsymbol{6})}$ also documented that the mean time of union was 3 months ( 13 weeks), ranged from 2 to 4 months.

According to radiological measurements, our results shows that there was significant improvement of Bohler angel from $11.4^{\circ}$ as the mean preoperative to $27.72^{\circ}$ postoperatively. Most of the patients (61.1\%) had Bohler angle less than $10^{\circ}$ preoperatively, while postoperatively $66.7 \%$ of them had Bohler angel between 25 and $35^{\circ}$.

Regarding the correlation between Bohler angle and AOFAS score there were no correlation between the preoperative Bohler angle and AOFAS score. While the postoperative Bohler angle had significant effect on the outcome as the satisfactory outcome had Bohler angle between 26 to $37^{\circ}$. And no single case with Bohler less than 24 had satisfactory AOFAS score.

This was comparable with Mallya et al. ${ }^{(9)}$ who documented the improvement of Bohler angle from $13.6^{\circ}$ (ranged from 1.2 to $20^{\circ}$ ) preoperatively to 21.8 ranged from $\left(8.7\right.$ to $\left.35^{\circ}\right)$ postoperatively. Also, they observed that there was highly statistical significance between postoperative Bohler angel and AOFAS score ( $\mathrm{P}$ value was 0.001 ), they noted that when postoperative Bohler's angle was more than 18 degrees, in total, one patient had an exceptional result, 20 patients had good results, 7 had mediocre results, and seven patients had bad results. Although no one got outstanding or good results when the postoperative Bohler's angle was less than 18 degrees, 
eight patients had a fair result and four patients had a poor result.

Also, Ebrahimpour et al. ${ }^{(11)}$ documented that the mean preoperative Bohler angel was $22.4 \pm 9.8^{\circ}$ and improved to $26 \pm 6.3^{\circ}$. While mean preoperative Gissane angle was $123.0 \pm 10.5^{\circ}$, which was improved to $115 \pm 7.2^{\circ}$ in the open reduction and internal fixation (ORIF) group. This result was better than the close reduction inte rnal fixation by screws group which had postoperative Bohler and Gissane of $23.9 \pm 7.9^{\circ}$ and $118.4 \pm 11.2^{\circ}$ respectively. Also Jain et $\boldsymbol{a l} .^{(\mathbf{1 2})}$, who had mean AOFAS score 86.3 ranged from 66 to 97, documented that the mean Bohler angle was 25.47. While Santosha et al. ${ }^{(8)}$, who had mean AOFAS score 79.9 ranged from 49 to 96 , the satisfactory results was $76.6 \%$, while unsatisfactory was $23.3 \%$, the mean preoperative Bohler was $12^{\circ}$ while mean postoperative Bohler was $32^{\circ}$. The mean AOFAS score in our results was 79.5 , which was lower than the other probably due to shorter time of follow up of our study.

Radiological measurements in this study had statistical significance improvement, as the Gissane angle improved from mean $132.17^{\circ}$ preoperatively to $120.15^{\circ}$ postoperatively. Calcaneal width improved from $40.89 \mathrm{~mm}$ to $38.25 \mathrm{~mm}$, and length also improved from $65.53 \mathrm{~mm}$ to $69.24 \mathrm{~mm}$.

This was comparable with Yeo et al. ${ }^{(10)}$, who documented the improvement of Gissane angle to $119^{\circ}$ ranged from $73.5^{\circ}$ to $145.6^{\circ}$, to $127.4^{\circ}$ postoperatively from mean preoperative $121.8^{\circ}$. While, the calcaneal width improved from $39.2 \mathrm{~mm}$ to 39.3 postoperatively, and the calcaneal length improved from 75.3 to $76.1 \mathrm{~mm}$.

Regarding the complications this study results showed that $61.1 \%$ of patients had no complications. While SSI occurred in $16.66 \%$ of patients, sural neuritis occurs in $11.11 \%$ while peroneal tendinitis, delayed union, subtalar arthritis occurs in $5.56 \%$.

These results were comparable with Jain and colleagues study ${ }^{(12)}, 3$ patients $(11 \%)$ had flap necrosis at the incision site, according to this study. Subtalar arthritis was found in five individuals (17\%), while sural nerve hypoesthesia was found in one patient (4\%). Mallya and colleagues ${ }^{(9)}$ reported Three patients had soft tissue complications, two of which had necrosis of the wound edge and one of whom had a superficial infection. According to culture reports, these issues were cured with regular dressings and antibiotics.

Finally according to meta-analysis conducted by Zeng et al. ${ }^{(13)}$ who observed that for Sanders type II displaced intra-articular calcaneal fractures, a minimally invasive method is superior than ORIF in terms of functional outcomes, which has a substantial impact on clinical outcomes. With the minimally invasive approach, calcaneal reduction is equivalent or better than with the ELA+ plate, but wound problems are greatly reduced.

\section{CONCLUSION}

The trans-calcaneal method of reduction through ELA is an excellent method for treatment of displaced intra-articular calcaneal fractures, as it provides good exposure and facilitates anatomical reduction of fracture. Radiological factors such as Bohler angle, Gissane angle, calcaneus dimensions like length, height, and width, and functional outcomes by employing the A.O.F.A.S. hindfoot scale when compared to other methodologies and methods of fixation, the results are equivalent and convincing.

\section{Financial support and sponsorship: Nil. Conflict of interest: Nil.}

\section{REFERENCES}

1. Rokaya P, Pokharel R, Lamichhane A (2016): Radiographic evaluation of calcaneal angles in patients presenting to tertiary care center of Nepal. J Inst Med., 38:33-6.

2. Melo E (2012): The calcaneus channel: A propos of a new anatomical variant. Clin Anat., 8(25):989-91.

3. Bemstein J, Ahn J (2010): Fractures in brief calcaneal fracture. Clin Orthop Relat Res., 468:3432-4.

4. Dhillon M, Prabhakar S (2017): Treatment of displaced intra-articular calcaneus fractures: a current concepts review. Sicot J., 3: 1-6.

5. Kiewiet N, Sangeorzan B (2017): Calcaneal fracture management: extensile lateral approach versus small incision technique. Foot Ankle Clin., 22(1):77-91.

6. Meraj A, Zahid M, Ahmad S (2012): Management of intraarticular calcaneal fractures by minimally invasive sinus tarsi approach-early results. Malaysian Orthop J., 6(1):13-7.

7. Nosewicz T, Knupp M, Barg A et al. (2012): Mini-open sinus tarsi approach with percutaneous screw fixation of displaced calcaneal fractures: a prospective computed tomography-based study. Foot ankle Int., 33(11):925-33.

8. Santosha, Gulrez S, Singh A, Waikhom S et al. (2016): Open reduction and internal fixation of displaced calcaneum, intra-articular fractures by locking calcaneal plate. J Clin Diagnostic Res., 10(12): 18-21.

9. Mallya S, Kamath R, Hegde A et al. (2018): Can Bohler's angle predict the functional results of intra-articular displaced calcaneal fractures? J Clin Diagnostic Res., 12(11):10-13.

10. Yeo J, Cho H, Lee K (2015): Comparison of two surgical approaches for displaced intra-articular calcaneal fractures: Sinus tarsi versus extensile lateral approach Orthopedics and biomechanics. BMC Musculoskelet Disord., 16(1):1-7.

11. Ebrahimpour A, Kord M, Sadighi M et al. (2021): Percutaneous reduction and screw fixation for all types of intra-articular calcaneal fractures. Musculoskelet Surg [Internet], 105(1):97-103.

12. Jain S, Jain A, Kumar I (2013): Outcome of open reduction and internal fixation of intraarticular calcaneal fracture fixed with locking calcaneal plate. Chinese $\mathrm{J}$ Traumatol = Zhonghua chuang shang za zhi., 16(6):355-60.

13. Zeng $Z$, Yuan L, Zheng $S$ et al. (2018): Minimally invasive versus extensile lateral approach for Sanders type II and III calcaneal fractures: A meta-analysis of randomized controlled trials. Int J Surg [Internet], 50:146-53. 